\title{
Pueblo Mágico de Valladolid
}

\section{Magical Town of Valladolid}

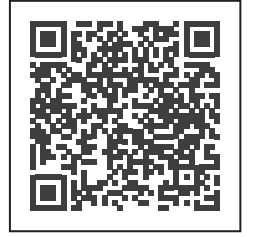

\section{Palabras clave:}

competitividad, economía, pueblo mágico, México, turismo.

\section{Keywords:}

Competitiveness; Economy; magic town; Mexico; Tourism.

Código JEL: Z320 Tourism and Development

Artículo de investigación

Fecha de recepción:

15 de marzo de 2021

Fecha de aprobación:

02 de agosto de 2021

Fecha de publicación:

16 de septiembre de 2021

Creative Commons

Reconocimiento-NoComercial-SinObraDerivada 4.0 Internacional

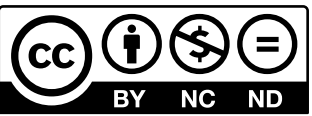

José Apolinar Zapata Aguilar¹; Olga Libia Cruz Díaz; Elisa Cabrera Ignacio3; Carlos Alberto Cupul Rosado ${ }^{4}$

\section{Resumen}

Problemática: México posee una riqueza cultural inigualable que incluye creencias, tradiciones y valores. Uno de sus principales atractivos son sus pueblos. Desde el año 2001, la Secretaría de Turismo ha reconocido a los más representativos con el distintivo de Pueblos Mágicos. Objetivo: el presente estudio de investigación valora el impacto del Programa Pueblos Mágicos en el municipio de Valladolid, Yucatán, México y discute sus efectos en la economía local. Materiales y métodos: el estudio contempló la realización de una encuesta por entrevista personal a autoridades de la actual administración del H. Ayuntamiento de Valladolid y de la gestión anterior, así como a empresarios, ciudadanos y turistas nacionales y extranjeros. Resultados y discusión: se encontró que gran parte de los beneficios económicos que genera el turismo es aprovechada por cadenas turísticas, que venden paquetes armados, lo que afecta a las empresas de la localidad. Conclusiones: el desafío para las autoridades, empresarios y ciudadanos del municipio,

1 Licenciado en Administración. Maestro en Administración. Doctor en Análisis Estratégico y Desarrollo Sustentable. Universidad Tecnológica Metropolitana. División de Administración, México. jose.zapata@utmetropolitana.edu.mx, ORCID: 0000-0002-1596-4916

2 Licenciada en Administración. Maestra en Comunicación Organizacional. Universidad Tecnológica Metropolitana. División de Administración, México. olga.cruz@utmetropolitana.edu.mx, ORCID: 0000-0002-6353-0346

3 Contador público. Maestra en Administración Financiera. Universidad Tecnológica Metropolitana. División de Administración, México. elisa.cabrera@ utmetropolitana.edu.mx, ORCID: 0000-0001-8615-4542

4 Licenciado en Administración. Maestro en Planificación de Empresas y Desarrollo Regional. Universidad Tecnológica Metropolitana. División de Administración, México. carlos.cupul@utmetropolitana.edu.mx, ORCID: 0000-0002-1913-2631 


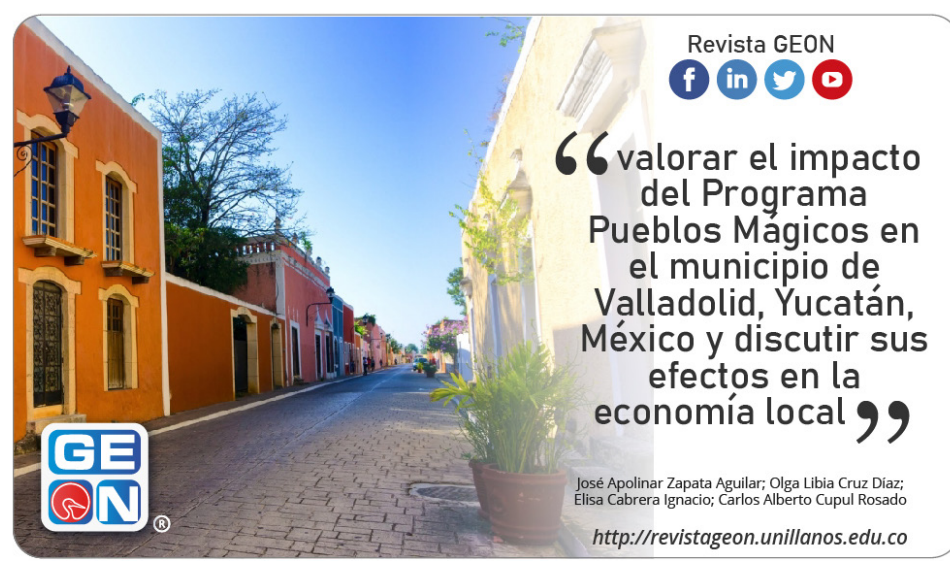

hoy en día, es impulsar el distintivo haciendo sinergia, es decir, integrando sus recursos para un mismo fin: el impulso del reconocimiento del municipio como Pueblo Mágico en los mercados turísticos del país y del extranjero, lo cual se espera que se traduzca en un mejoramiento de la economía local que contempla a empresarios y ciudadanos, reforzando uno de los fines originales del programa, que es incrementar la calidad de vida de los ciudadanos por medio de la obtención de mejores ingresos provenientes del turismo.

Palabras clave: competitividad, economía, pueblo mágico, México, turismo.

Código JEL: Z320 Turismo y Desarrollo

\section{Abstract}

Troublesome: Mexico has an unmatched cultural wealth that includes beliefs, traditions and values. One of its main attractaions are its towns, within which the Secretary of Tourism has recognized since 2001, the most representative with a distinctive called: Magital towns. Objetive: this research study assesses the impact of the aforementioned program in the municipality of Valladolid, Yucatán, México and discusses its effects on the local economy. Materials and methods: the study contemplad the realization of survey by personal interview to autorities of the current administration of $\mathrm{H}$. City 
Cómo citar este artículo /

Toreference this article:

Zapata Aguilar, J. A., Cruz Díaz, O L., Cabrera Ignacio, E., \& Cupul Rosado, C. A. (2021). Pueblo Mágico Valladolid. Revista GEON (Gestión, Organizaciones Y Negocios), 8(2), e-307. https://doi. org/10.22579/23463910.307
Council of Valladolid and of the previous administration, businessmen, citizens and national and foreign tourists. Results and discussion: einding that a large part of the economic benefits generated by tourism is taken advantage of by tourism chains, which sell armed packages, affecting local companies. Conclusions: the challenge for the autorities, businessmen and citizens of the municipality today is to promete the distinctive by making synergy, that is, integrating its resources for the same purpose, promoting the recognition of the municipality as a magical town to the tourist markets of the country and the foreigner, which is expected to translate into an improvement of the local economy, which includes enterpreneurs and citizen, reinforcing one of the original purposes of the program, which is to raise the quality of life of citizens by obtaining better incomes from of tourism.

Keywords: Competitiveness; Economy; magic town; Mexico; Tourism.

Código JEL: Z320 Tourism and Development

\section{Introducción}

Los pueblos son el reflejo de la cultura de un país, marcan el origen de sus pobladores y están envueltos de creencias y tradiciones únicas que los hacen atractivos a los ojos del mundo. Transitar por un pueblo, disfrutar de su gastronomía y respirar sus aromas, genera en los visitantes, experiencias inigualables. El descubrir un pueblo mágico es sumergirse en un mundo diferente, donde las novedades son el inicio de una aventura que se convertirá en un abanico de recuerdos. El municipio de Valladolid, Yucatán, México no es la excepción, ya que es una de las joyas del estado de Yucatán, comu- nidad con una riqueza natural y arquitectónica exquisita, que no solo atrae al turismo extranjero, sino al nacional que, cautivado con su belleza y atracciones únicas, visita el Pueblo Mágico de manera recurrente. La cercanía de Chichén Itzá, nueva maravilla del mundo moderno, y de Cancún, Quintana Roo, centro turístico por excelencia del sureste mexicano, hacen de Valladolid una ciudad que los turistas que se transportan por vía terrestre tienen que atravesar en su recorrido. La cordialidad de su gente crea ambientes agradables y atractivos para el visitante, invitándolo a permanecer más tiempo en el lugar y a disfrutar su estancia en cada espacio visitado. 
La calidez refrenda la amabilidad del yucateco, haciendo del lugar un espacio mágico y memorable. El presente estudio de investigación valora el impacto del Programa Pueblos Mágicos en el municipio de Valladolid, Yucatán, México y discute sus efectos en la economía local. El estudio contempló una encuesta por entrevista personal a las autoridades de la actual administración del H. Ayuntamiento de Valladolid y de la gestión anterior, así como a empresarios, ciudadanos y turistas nacionales y extranjeros, quienes expresaron su opinión respecto a cómo visualizan el impacto del programa en su territorio.

\section{Contexto teórico}

El turismo es incierto debido a que depende de factores visibles e incontrolables, ya que está sujeto a paisajes, mareas, calidad del medio ambiente, recursos, pero, sobre todo, a estrategias de promoción del territorio. La economía turística se ve afectada por la tensión que se da entre la naturaleza atractiva, y a la vez depredadora, y su dependencia con el paisaje que impacta (Rubio, 2017).

De acuerdo con Coll-Hurtado (2016), el turismo es una actividad que involucra varios elementos diversos que forman parte del sector servicios. Es una actividad con dimensiones de tipo económico, social, político, ambiental, cultural y territorial. En otras palabras, de dimensión geográfica.

La disposición de lugares dedicados al turismo en México, como parte de una estrategia de impulso de los gobiernos, ha permitido la diversifica- ción de las actividades económicas y productivas de muchos espacios territoriales. A este hecho se suma el interés de los administradores municipales por impulsar nuevos productos turísticos debido a las bondades que brindan al desarrollo local, que se materializan en la diversificación económica y la generación de empleo e ingresos para la población de la localidad (Vázquez \& Vázquez, 2017).

En México, el turismo es una actividad económica que también se encuentra al alza y, sin tomar en cuenta los matices ideológicos de los diferentes partidos políticos, se ha establecido como una prioridad. Los tres órdenes de gobierno (municipal, estatal y federal) consideran que el apoyo a dicha actividad es una manera efectiva de lograr el desarrollo económico y el bienestar de los ciudadanos de una sociedad (Osorio \& López, 2012).

México está integrado por 32 estados, distribuidos en siete regiones: norte, noreste, occidente central, central, del golfo, del sur y península de Yucatán. Cada región está conformada por entidades que presentan características similares, ya sea de tipo físico, cultural o económico. Yucatán pertenece a la región península de Yucatán, junto con los estados de Quintana Roo y Campeche. Esta organización atiende a características físicas y geográficas de las entidades agrupadas por regiones. La calidad observada de un servicio puede ser utilizada a nivel estratégico por las entidades, de tal manera que contribuya a la estructura y operatividad a nivel organizacional, con base en los facto- 
res que los clientes incluyen entre sus experiencias, percepciones y necesidades (Monroy \& Urcádiz, 2020).

El turismo es una de las actividades económicas que genera mayor número de empleos. Su explotación es casi siempre a través de concesiones a empresarios privados para el aprovechamiento de áreas próximas a los destinos que presentan características diferenciadas, como son haciendas, cenotes, museos, zonas arqueológicas, entre otros. En el caso de Valladolid, el aprovechamiento de los turistas, que provienen principalmente de la ciudad de Cancún rumbo a Chichén Itzá, se da por algunas instalaciones hoteleras, restaurantes y escasos comercios. De esta forma, Valladolid se convierte en un punto de paso y no en un destino como tal (UADY, 2012).

De acuerdo con Pérez et al. (2016), a la fecha, el turismo representa una de las actividades económicas más importantes del país, debido a que se vuelve un significativo impulsor económico que genera importantes desarrollos de empresas hoteleras, gastronómicas y parques temáticos, los cuales dan lugar a la creación de proyectos de infraestructura que facilitan el acceso, además de un crecimiento en el número de vehículos que transitan por vía terrestre, aérea y marítima, sin omitir la generación de puestos de trabajo que coadyuvan al desarrollo económico, político y cultural de cualquier sociedad.

Por su parte, Otero et al. (2015) mencionan que aquellos lugares turísticos que logran identificar lo que motiva y atrae a sus visitantes tienen muchas más posibilidades de mantenerse en un contexto competitivo. Por otro lado, López et al.(2018) exponen que el Programa Pueblos Mágicos tiene varias tareas por realizar. Entre ellas está la integración de los posibles escenarios locales, bajo una visión que va más allá de la mercantilista. se requiere fortalecer y rescatar la memoria, sin sacrificar la innovación, promover el conocimiento y el cuidado del medio ambiente (Jaramillo, 2021), pero, sobre todo, procurar el respeto por la ideología de las personas, la cultura y la naturaleza.

La manera en que la población percibe a los visitantes se convierte en un factor clave en el desarrollo turístico de la localidad, ya que los habitantes tienen formas de vida cimentadas en sus costumbres, trayectoria e historia, pero quedan influenciadas por las experiencias que dejan los visitantes de otros lugares cuando llegan a una comunidad (Méndez et al., 2016).

\section{Materiales y métodos}

Para el estudio realizado se tomaron como referencia cuatro tipos de poblaciones: autoridades, que contempló funcionarios, tanto de la gestión anterior como de la actual, turistas nacionales y extranjeros, pobladores del municipio $y$, finalmente, empresarios de Valladolid, Yucatán. En el primer grupo de participantes se encuestó una muestra de cinco autoridades del período del gobierno anterior (2015-2018) y de cinco autoridades del período del gobierno actual (2018-2021). 
En el segundo grupo se encuestó una muestra de 229 turistas tanto nacionales como extranjeros, para lo cual el equipo de investigación tradujo el cuestionario diseñado al idioma inglés, con la finalidad de que los turistas extranjeros pudieran escuchar las preguntas en inglés y responder en su idioma. En el tercer grupo se encuestó una muestra de 383 ciudadanos del municipio de Valladolid $y$, finalmente, se encuestó una muestra de 233 empresarios de Valladolid de una diversidad de tipos de negocio, principalmente los relacionados de manera directa o indirecta con la actividad turística.

En los cuatro grupos encuestados se utilizó un cuestionario con preguntas de opción y de código múltiple. Según Hernández et al. (2006), el cuestionario es un instrumento de recolección de información, conformado por un conjunto de preguntas con respecto a una o más variables que se deseen medir. Dicho instrumento fue ideal para el estudio realizado en virtud de que se manejaron las mismas variables en los cuatro instrumentos aplicados.

El trabajo de campo se realizó durante 72 días. En el caso de las autoridades y los empresarios, se acudió a ellos con cita previa y se les aplicó el cuestionario a manera de entrevista, mientras que en el caso de los turistas, se acudió a sus principales centros de concentración en horarios específicos y se les fue abordando para aplicarles el instrumento a manera de entrevista personal. A los turistas nacionales se les abordó en su visita al centro histórico de Valladolid.
En cuanto a los ciudadanos, se les encuestó abordándolos en su tránsito por el primer cuadro de la ciudad de Valladolid, Yucatán.

La recolección de la información se realizó de manera física y posteriormente se capturó a través de Google forms. Una vez capturada la información, se descargó la base de datos en Excel y se procedió a su revisión, con la finalidad de limpiarla, verificando que todos los datos hubieran sido capturados de manera correcta. Luego de la validación de la base de datos, se realizó el análisis de la información recopilada, comparando la información documental obtenida de fuentes primarias y secundarias con lo hallado en la encuesta, para explicar el impacto que los encuestados han observado de la implementación del Programa Nacional de Pueblos Mágicos en el municipio de Valladolid.

\section{Resultados}

El turismo es la principal actividad económica del Pueblo Mágico de Valladolid, Yucatán. Esto queda constatado al coincidir las respuestas de los empresarios, ciudadanos y autoridades del municipio, ya que cuando se les preguntó si consideraban al turismo como principal actividad económica, más del 50\% respondió afirmativamente (figura 1).

Las autoridades encuestadas manifestaron que entre las actividades económicas asociadas al turismo que se han desarrollado en el Pueblo Mágico de Valladolid en los últimos tres años se encuentran el ecoturismo, la 
venta de alimentos tradicionales, entre otros. A partir del reconocimiento de la comunidad como Pueblo Mágico, las mejoras que ha realizado el gobierno en materia de infraestructura, servicios públicos, calles, espacios públicos y nuevos comercios han sido mínimas. Las autoridades del municipio de Valladolid afirman que las instituciones, tanto del gobierno federal como estatal, no ofrecen a la comunidad un trato especial por ser un Pueblo Mágico.

Figura 1. Percepción del turismo como principal actividad económica del Pueblo Mágico de Valladolid. Fuente: encuesta a empresarios, ciudadanos y autoridades del Pueblo Mágico de Valladolid, Yucatán (2020).

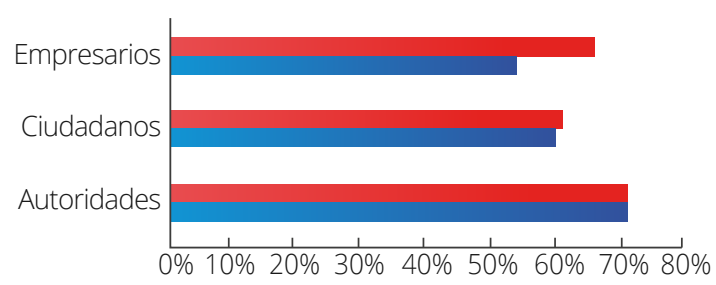

Turismo actividad económica que genera más ingresos Turismo principal actividad económica

Lo anterior ha llevado a la población a interesarse por desarrollar actividades asociadas al turismo, que van desde comercios que ofrecen alimentos, bebidas o artesanías hasta una diversidad de servicios orientados al turista (figura 2).

Los ciudadanos afirman que quienes más se benefician del turismo son los empresarios y comerciantes, seguidos de las autoridades. Una minoría considera que el turismo beneficia a toda la comunidad (figura 3).
Figura 2. Interés de la comunidad por emplearse en actividades asociadas al turismo (comercio / servicios). Fuente: encuesta a ciudadanos del Pueblo Mágico de Valladolid, Yucatán (2020).

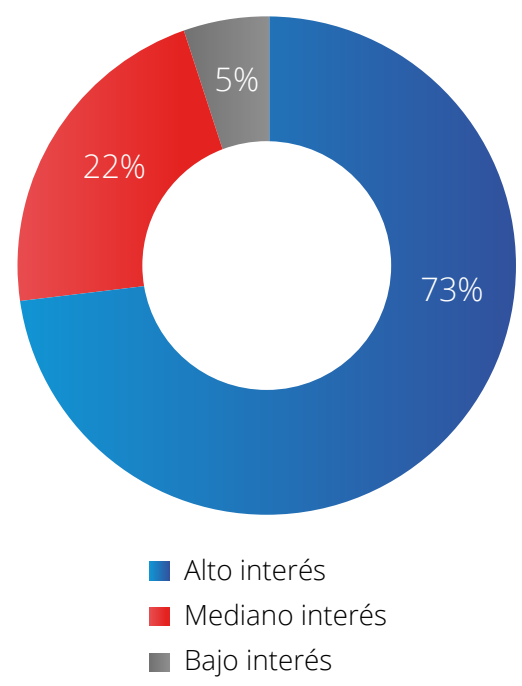

Figura 3. Beneficiados del turismo. Fuente: encuesta a ciudadanos del Pueblo Mágico de Valladolid, Yucatán (2020).

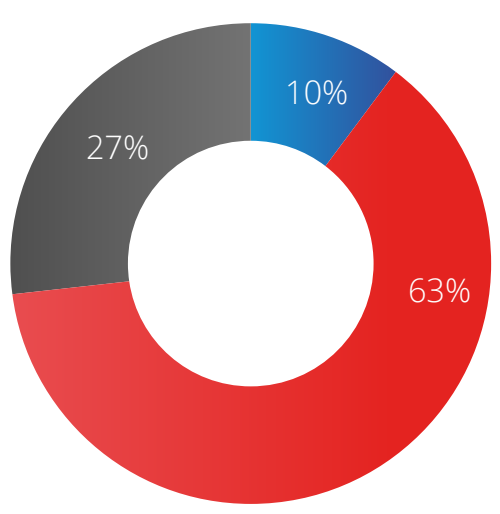

- Toda la comunidad

- Empresarios y comerciantes

Autoridades

Los ciudadanos encuestados afirman que más del 69\% de las inversiones realizadas en el Pueblo Mágico de Valladolid son externas, lo que significa que los propietarios de las nuevas 
empresas no son ciudadanos de la comunidad, sino inversionistas externos que, interesados en el potencial del Pueblo Mágico, deciden invertir en él, ya que observan la afluenc ia turística diaria y el dinamismo que genera.

Los ciudadanos abordados en la encuesta afirman que, si bien el turismo ha contribuido al crecimiento del empleo entre la población, este ha sido temporal (figura 4), lo que no permite a la ciudadanía percibir ingresos de manera permanente que coadyuven a mejorar gradualmente la calidad de vida.

Figura 4. Tipo de empleo al que ha contribuido el turismo. Fuente: encuesta a ciudadanos del Pueblo Mágico de Valladolid, Yucatán (2020).

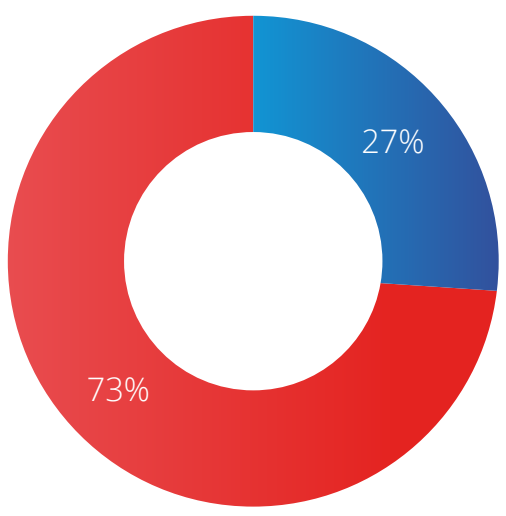

Figura 5. Ingresos de las empresas en los últimos tres años. Fuente: encuesta a empresarios del Pueblo Mágico de Valladolid, Yucatán (2020).

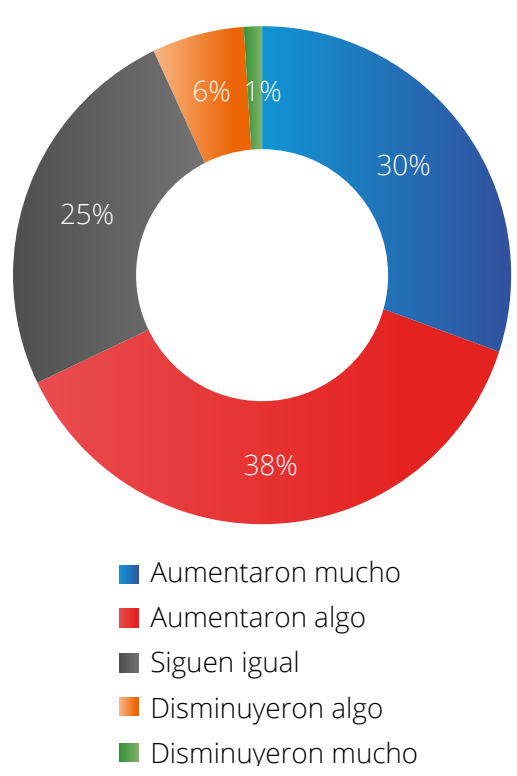

Más del 50\% de los empresarios considera que el Programa Pueblos Mágicos favoreció a la comunidad en virtud de que despertó el interés del turismo nacional e internacional por conocer Valladolid, beneficiado por la cercanía con Chichén Itzá y Cancún, Quintana Roo.

Con respecto a los visitantes, fue muy satisfactorio encontrar más turismo nacional que internacional, ya que en la muestra abordada el $77 \%$ de los visitantes fue de nacionalidad mexicana y el $23 \%$ de otras nacionalidades, como norteamericanos, canadienses, entre otros, lo que permite observar un mayor interés del turismo nacional por conocer nuevos Pueblos Mágicos de su país.

En cuanto a la percepción de los visitantes sobre el alojamiento, el trans- 
porte y la hospitalidad, los hallazgos fueron satisfactorios, ya que el grueso de la muestra los calificó de buenos a excelentes, lo que permite observar que el Pueblo Mágico de Valladolid, Yucatán es un producto de calidad, atractivo tanto para el turismo nacional como para el extranjero (figuras 6 a 8).

Figura 6. Calificación por tipo de alojamiento según los visitantes. Fuente: encuesta a visitantes del Pueblo Mágico de Valladolid, Yucatán (2020).

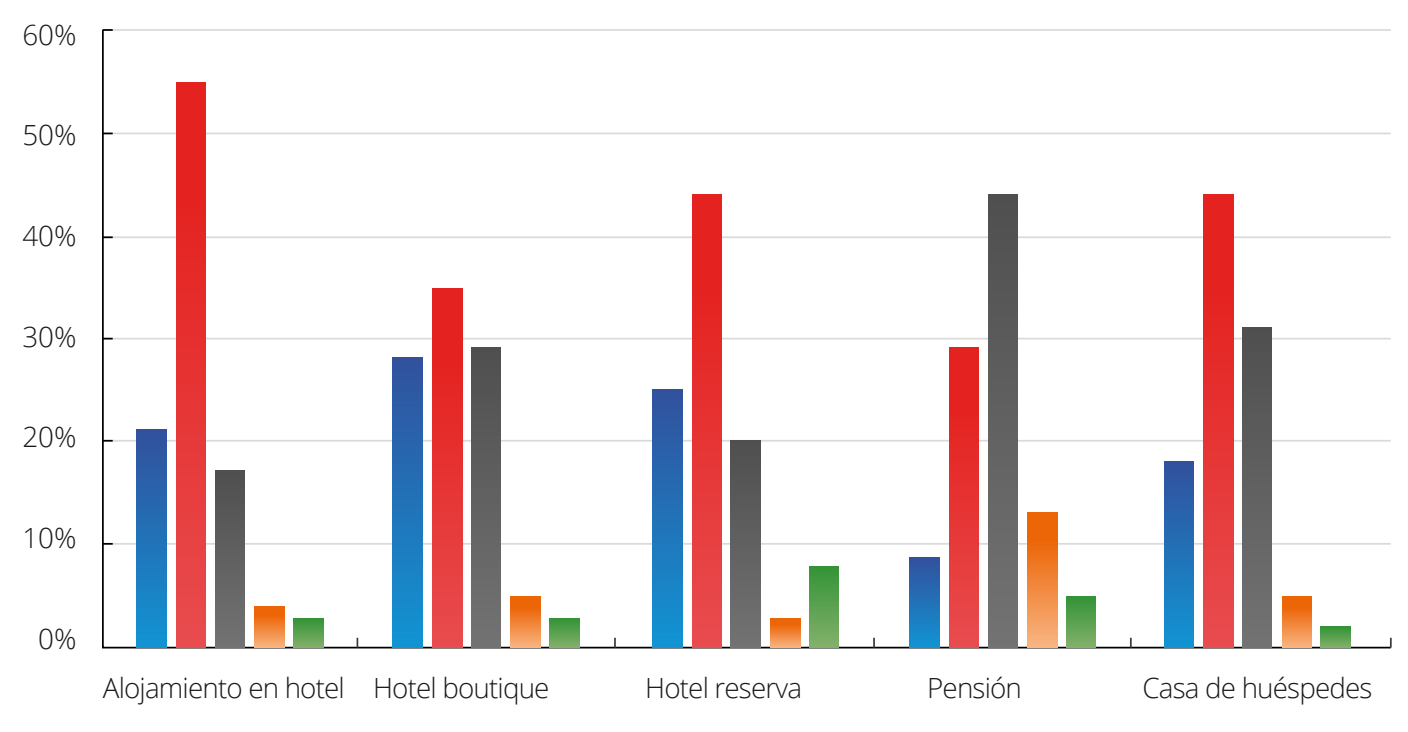

Excelente Bueno negular Malo aPésimo

Figura 7. Calificación del transporte según los visitantes. Fuente: encuesta a visitantes del Pueblo Mágico de Valladolid, Yucatán (2020).

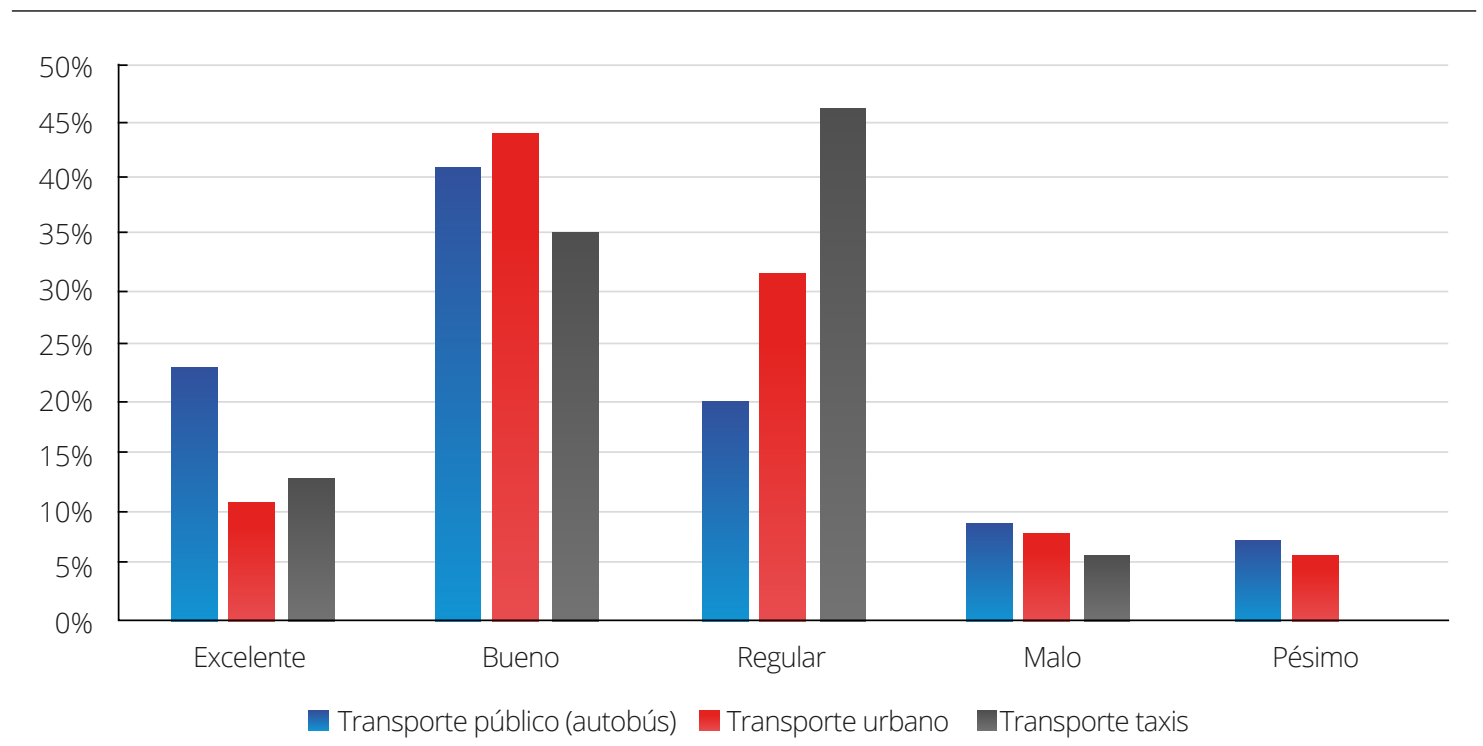


Figura 8. Calificación de la hospitalidad según los visitantes. Fuente: encuesta a visitantes del Pueblo Mágico de Valladolid, Yucatán (2020).

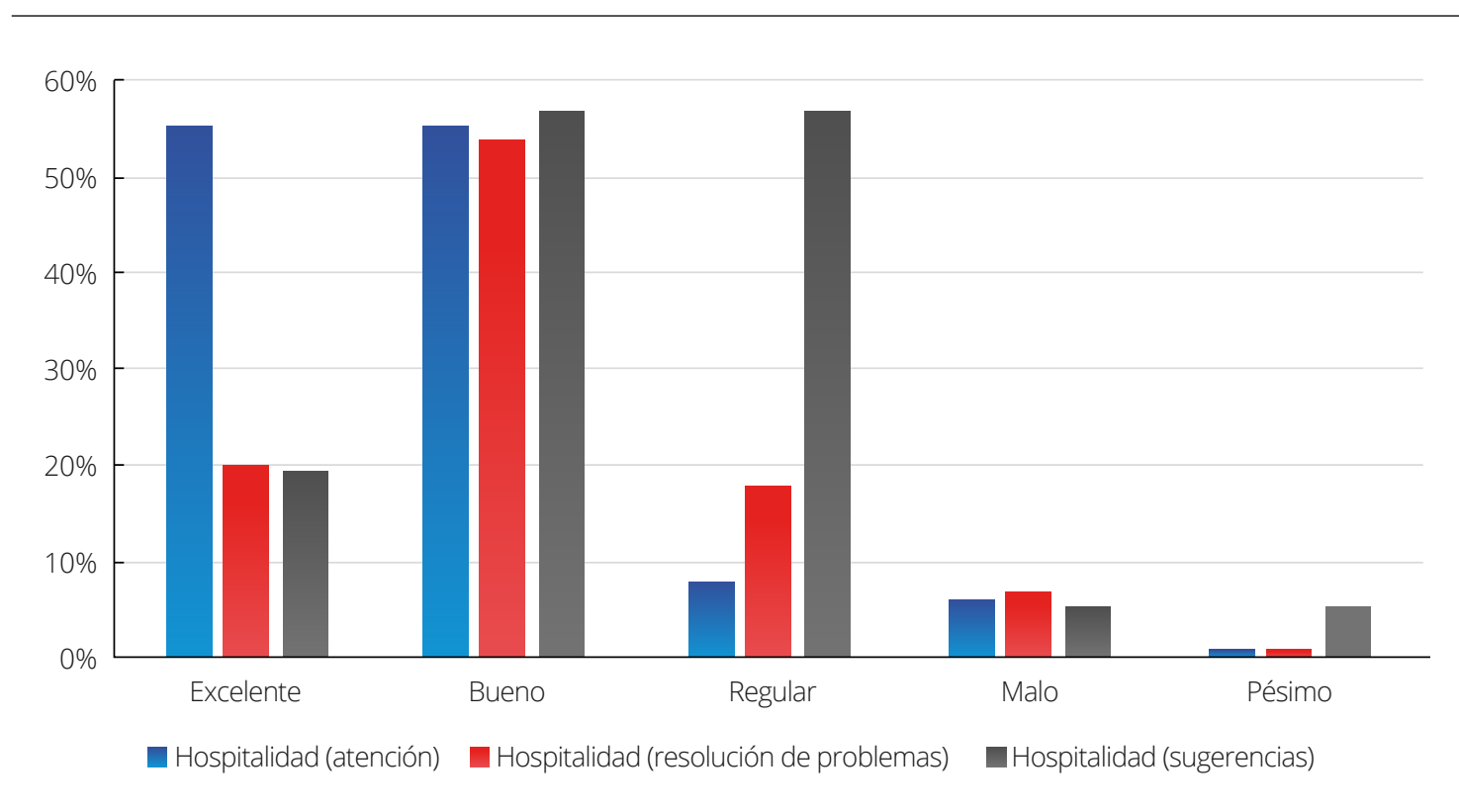

Una característica del yucateco y en especial del vallisoletano es su inigualable hospitalidad, que no solo quedó confirmada con los hallazgos encontrados en la encuesta, sino que se puede palpar cuando se llega a la comunidad, se solicita un servicio o se compra algún producto. El ciudadano y el comerciante demuestran una actitud que no solo agrada, sino que invita al visitante a permanecer más tiempo en el lugar, el cual cuenta con monumentos históricos, cenotes y espacios coloniales de gran belleza arquitectónica, rodeados de una exuberante naturaleza que refresca cada rincón de este maravilloso Pueblo Mágico.

Una de las características de este Pueblo Mágico es su seguridad, ya que los pobladores se conocen e interactúan entre sí y están atentos a cualquier suceso que ocurre en el municipio. De hecho, más del 50\% de los visitantes encuestados afirma que Valladolid es una comunidad segura (figura 9).

Figura 9. La seguridad en Valladolid. Fuente: encuesta a visitantes del Pueblo Mágico de Valladolid, Yucatán (2020).

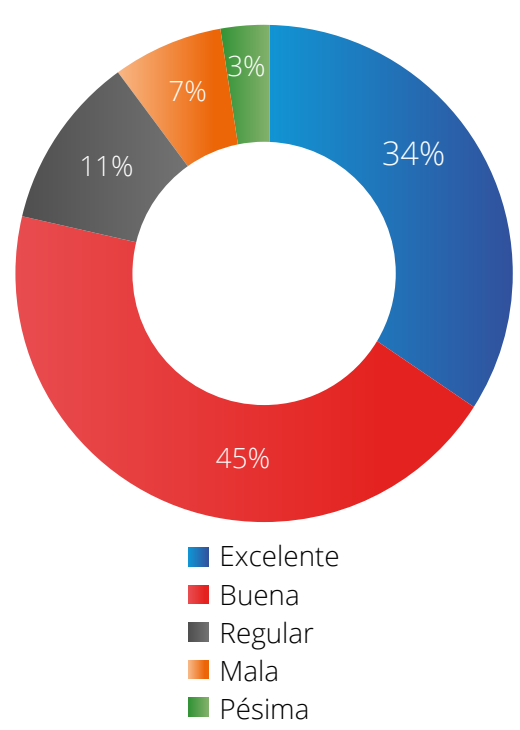




\section{Discusión}

De acuerdo con lo hallado, Valladolid cuenta con características únicas que lo hacen un inigualable Pueblo Mágico que, a partir de su nombramiento, ha despertado gran interés y expectativa en el turismo nacional e internacional, beneficiado también por su localización geográfica entre la zona arqueológica de Chichén Itzá y la zona turística de Cancún, Quintana Roo.

En el estudio se encontró que aun cuando el Pueblo Mágico de Valladolid depende económicamente en gran medida del turismo, de acuerdo con sus ciudadanos, empresarios y autoridades, también es una realidad que gran parte de ese turismo, principalmente extranjero, llega al municipio a través de tours organizados por empresas privadas, las cuales controlan los tiempos de los turistas en el Pueblo Mágico y les ofrecen servicios de alimentos y hospedaje en su siguiente escala, que normalemente es la ciudad de Cancún, Quintana Roo.

Lo anterior reduce la posibilidad de los empresarios del municipio de obtener ingresos directos por la comercialización de bienes y servicios, y a los ciudadanos, de tener un empleo en el sector turístico, razón por la que orientan su oferta al turista nacional, quien en ocasiones no solo es selectivo, sino que suele comparar lo recibido con lo que ha experimentado en sus visitas a otros Pueblos Mágicos. De acuerdo con los datos obtenidos, Valladolid cuenta con las instalaciones y los servicios necesarios para recibir más turismo, por encima del que llega en su tránsito a Cancún, Quintana Roo o a Chichén Itzá.

Aunque las autoridades y los empresarios manifiestan que el municipio no ha recibido un trato preferencial por ser Pueblo Mágico, también expresan que han sido ellos, junto a los ciudadanos, quienes han trabajado por proyectar y conservar este distintivo para atraer el turismo nacional e internacional a través de una experiencia que haga que el turista se sienta satisfecho con su visita al Pueblo Mágico, lo recomiende y decida regresar.

\section{Conclusiones}

El Pueblo Mágico de Valladolid enfrenta grandes retos, toda vez que los beneficios del programa, en sus inicios, permitieron a los ciudadanos, empresarios, autoridades y trabajadores del sector turístico crear identidad al resaltar cualidades únicas del municipio alrededor de su historia, cultura y gastronomía. La identidad es una de las principales ventajas competitivas de este Pueblo Mágico.

El sector turístico se ha transformado en el municipio de Valladolid, ya que en el pasado el turista extranjero llegaba por propio pie, se hospedaba en los hoteles, comía en los restaurantes del municipio, hacía recorridos, consumiendo los productos locales, ocupaba el transporte, generando ingresos para la población de manera directa e indirecta. El beneficio económico para los trabajadores del sector era efectivo.

Lo que ha sucedido es que las grandes cadenas de servicios turísticos se 
han agrupado para ofrecer paquetes de servicios a los turistas que incluyen hospedaje, alimentación y transporte. Esto resulta atractivo para los turistas económicamente hablando, pero muy dañino para la población del municipio de Valladolid que trabaja en el sector turístico porque deja de percibir ingresos.

El municipio también enfrenta hoy en día nuevas problemáticas que dañan su imagen como atractivo turístico, como es el control de la basura, el tránsito y las plagas de perros callejeros. Estas problemáticas quedan visibles al turista, ocasionando incomodidad y descontento, principalmente por la contaminación y el mal olor que generan la basura cuando se empieza a descomponer.

Existe una percepción positiva del Programa Pueblos Mágicos entre los ciudadanos, los empresarios y las autoridades. No obstante, estos también manifiestan la inminente falta de recursos para mejorar la infraestructura del municipio que permita a la ciudad ser más funcional y contar con tecnología que facilite la conectividad y el aprovechamiento de las riquezas naturales que posee el municipio.

El turista nacional es mucho más exigente que el internacional porque es el que, por lo general, transita en la ciudad y hace uso de los productos y servicios locales, y suele compararlos con los que ha adquirido en otros municipios del país, incluyendo otros Pueblos Mágicos. Así mismo, suele señalar y compartir la experiencia, resaltando principalmente lo que no fue de su agrado.
El municipio tendrá que reinventarse para aprovechar esta distinción, pero a falta de recursos públicos que permitan desarrollar proyectos turísticos, deberá aliarse con la sociedad civil y los empresarios para invertir en infraestructura y habilitación de espacios públicos, y vigilar que los beneficios de lo que se mejore vuelvan a llegar a los trabajadores del sector, a los empresarios y a la ciudadanía, para que, de esta manera, se active la economía local y se fortalezca el Pueblo Mágico, icono de la cultura en el estado de Yucatán.

El presente estudio de investigación será un referente para el desarrollo de estudios similares en el futuro que resalten la importancia del turismo como detonador económico de las regiones, así como de la manera en que permite a los habitantes tener poder adquisitivo derivado de los ingresos que genera la actividad turística, dinamizando el consumo y la circulación del efectivo en el Pueblo Mágico.

\section{Referencias}

Coll-Hurtado, A. (2016). Espacio y ocio: el turismo en México, (Colección: Temas Selectos de Geografía de México. I. Textos monográficos, 5. Economía), Instituto de Geografía, Universidad Nacional Autónoma de México, MéxiCO, 168 pp., ISBN 978-607-02-85059. Investigaciones geográficas, (92). https://doi.org/10.14350/rig.59443

Hernández, R., Fernández, C. \& Baptista, P. (2006). Metodología de la investigación. Mc Graw Hill.

Jaramillo Lotero, R. A. (2021). Una mirada a la competitividad. Dicta- 
men Libre, (20), 87-98. https://doi. org/10.18041/2619-4244/dl.20.2893

López, L., Valverde, C. \& Figueroa M. (2018) Pueblos Mágicos. Una visión interdisciplinaria (vol. IV). UAM Xochimilco-UNAM.

Méndez, A., García, A., Serrano, M. \& Ibarra, V. (2016) Determinantes sociales de la viabilidad del turismo alternativo en Atlautla, una comunidad rural del Centro de México. Investigaciones Geográficas (Mx), (90),119-134.[fecha de Consulta 13 de Septiembre de 2021]. ISSN: 0188-4611. Disponible en: https://www.redalyc.org/articulo. oa?id=56946869006

Monroy, M., \& Urcádiz, F. (2020). Percepción de turistas nacionales y foráneos del servicio en restaurantes de Todos Santos Pueblo Mágico, México. Visión de futuro, 24(2). https:// doi.org/10.36995/j.visiondefuturo.2020.24.02.006.es

Osorio, M. \& López, A. (2012). Investigación turística: Hallazgos y aportaciones. Investigaciones geográficas, (80)142-144. Recuperado en 13 de septiembre de 2021, de https://bit. ly/3EcYtPq
Otero Gómez, M. C., Giraldo Pérez, W., \& Torres Duarte, L. K. (2015). El posicionamiento de Villavicencio como destino turístico internacional y su aporte a la construcción de marca ciudad. Revista GEON (Gestión, Organizaciones $Y$ Negocios), 2(2), 43-47. https://doi. org/10.22579/23463910.94

Pérez, A., Fernández, A., Torralba, A. \& Cruz, J. (2016). Certificación del Turismo como área de oportunidad en el estado de Puebla en México. International Journal of Scientific Management Tourism, 2(2)329-351.

Rubio, I. (2017) Un destino incierto. Expansión del turismo, daños y riesgos ambientales en la costa de Oaxaca. Acta sociológica, (73)83-122. https:// doi.org/10.1016/j.acso.2017.08.003

UADY (2012). Diagnóstico de competitividad y sustentabilidad de los Pueblos Mágicos. UADY. https://bit.ly/2XfhnnM

Vázquez, G. \& Vázquez, V. (2017) Evaluación de recursos naturales y culturales para la creación de un corredor turístico en el altiplano en el altiplano de San Luis Potosí, México. Investigaciones geográficas, (94). https://doi. org/10.14350/rig.56575 